TITLE:

\title{
Module assembly for designing multivalent mid-sized inhibitors of protein-protein interactions.
}

\author{
$\operatorname{AUTHOR}(\mathrm{S})$ :
}

Ohkanda, Junko

CITATION:

Ohkanda, Junko. Module assembly for designing multivalent mid-sized inhibitors of protein-protein interactions.. Chemical record 2013, 13(6): 561-575

ISSUE DATE:

2013-12

URL:

http://hdl.handle.net/2433/199596

\section{RIGHT:}

This is the peer reviewed version of the following article: Ohkanda, J. (2013), Module Assembly for Designing Multivalent Mid-Sized Inhibitors of Protein-Protein Interactions. Chem. Rec., 13: 561-575, which has been published in final form at http://dx.doi.org/10.1002/tcr.201300026. This article may be used for non-commercial purposes in accordance with Wiley Terms and Conditions for Self-Archiving.; This is not the published version. Please cite only the published version.; この論文は出版社版でありません。引用の際には出版社版をご確認ご利用ください。 


\title{
Module Assembly for Designing Multivalent Mid-sized Inhibitors of Protein-protein Interactions
}

\author{
Junko Ohkanda \\ Institute for Chemical Research, Kyoto University, Gokasho, Uji, Kyoto 611-0011 (Japan) \\ E-mail: johkanda@scl.kyoto-u.ac.jp
}

\begin{abstract}
Developing clinically relevant synthetic agents that are capable of disrupting protein-protein interactions (PPIs) is now a major goal of scientific research. In an effort to explore new methodologies that are applicable to the design of synthetic PPI inhibitors, we examined a strategy based on the assembly of small module compounds to create multivalent mid-sized agents. This personal account describes three particular approaches based on module assembly: metal-chelating-based ligand assembly, covalent chemical ligation templated by a targeted protein, and bivalent inhibitor design for simultaneous targeting of the active pocket and protein surface. These strategies were shown to be useful for synthesizing minimally sized synthetic agents for targeting PPIs and may enable development of agents that are applicable to inhibition of intracellular PPIs.
\end{abstract}

Keywords: protein-protein interactions, mid-sized molecules, metal complexes, target-guided inhibitor synthesis, dual inhibitors, farnesyltransferase, type-I geranylgeranyltransferase, K-Ras

\section{Introduction}

Protein-protein interactions (PPIs) play a critical role in regulating signaling pathways in living systems, and dysregulation of PPIs is the mechanism of a large number of diseases. ${ }^{1}$ The number of PPIs in humans is estimated to be approximately $650,000,{ }^{2}$ representing a substantial number of new clinical targets for development of therapeutic agents. Despite their therapeutic relevance and abundance, however, PPIs have not traditionally been considered as targets by the pharmaceutical industries due to the large and featureless nature of protein-protein interfaces, which precludes the effective binding and action of low-molecular-weight compounds. However, tremendous insights regarding PPIs have emerged from recent interdisciplinary research efforts and are now shedding light on many possible strategies and technologies to address the large interfaces implicated in PPIs. For example, the discovery that most of the binding energy of protein complexes is contributed by only subsets of amino acid residues ${ }^{3}$ has prompted researchers to search for synthetic molecules that bind to such "hotspots". ${ }^{\text {1a }}$ In addition, recent biophysical studies revealed that protein interfaces are dynamic and can be flexible in solution, ${ }^{4}$ thus highlighting opportunities for identifying allosteric inhibitors. ${ }^{5}$ These advances in the understanding of PPI mechanisms have led many pharmaceutical companies to focus their interests on protein interfaces as potential drug targets. ${ }^{6}$ Nonetheless, developing drug-like 
small inhibitors of PPIs remains challenging. In fact, only a few small PPI inhibitors (molecular weight [MW] <500 Da) have been developed to date.

We are interested in a group of molecules ranging in MW between roughly 600 and 2,000 Da as potential scaffolds for the development of PPI-directed agents. Although these relatively large molecules have been disregarded recently by pharmaceutical companies because many of them do not conform to Lipinski's rule of five for drug-likeliness, we expected that their large molecular surface would allow for the introduction of multivalency and structural diversity, characteristics that are necessary for protein surface recognition. Recent examples, including the antitumor drug Eribulin (MW $730 \mathrm{Da}$ ), the Bcl-2 (B-cell lymphoma 2) inhibitor ABT-263 (MW $975 \mathrm{Da}$ ), and the integrin antagonist SAR1118 (MW 637 Da), have highlighted the potential applications of mid-sized molecules in therapeutics. ${ }^{7}$ Furthermore, promising new technologies for generating chemical libraries of macrocyclic peptides ${ }^{8}$ and heterocycles ${ }^{7}$ have recently been developed, and these libraries would allow for easier access to potential lead compounds of PPI inhibitors. This personal account describes our recent efforts focused on the development of a new methodology for PPI-directed agents based on mid-sized molecules.

\section{Module Assembly Strategy}

Antibody-based drugs are one example of successful biologics, and they are currently the only practical PPI-directed drugs in bedside use. However, these agents have several drawbacks associated with their inherent large molecular size (which hampers cell penetration) and their low bioavailability and high cost of production. From the viewpoint of developing alternative agents that compensate for these drawbacks, synthetic mid-sized agents are particularly attractive as they may allow us to decrease the MW by more than two orders of magnitude and thus increase cell penetration and plasma stability. Synthesizability would also reduce the production cost. However, several questions must be answered for this strategy to be successful: 1) what is the most practical strategy for introducing the structural characteristics necessary for the surface binding of a synthetic molecule?, and 2) how can we reduce molecular size while retaining the binding affinity and selectivity of the agents?

In an effort to address these questions, we began exploring a new approach for molecular design based on a module assembly strategy. This simple approach consists of three steps. First, the protein surface of interest is divided into several local regions based on structural features (e.g., cavity, charge, hydrophobicity, etc.). Second, relatively small organic molecules are designed as module compounds by introducing appropriate functional groups for complementary binding to each region. Finally, these modules are assembled by various means to build a multivalent mid-sized agent, which has higher binding affinity for large protein surfaces than does either module component alone.

Figure 1 illustrates the concepts of several approaches for constructing PPI inhibitors, based upon the idea described above. We anticipated that the formation of metal complexes with ligands 
containing various functional groups would facilitate introduction of synthetic antibody-like structural diversity into the agents. The resulting metal-complex libraries may be useful for identifying lead compounds for various protein targets (Fig. 1a). We hypothesized that target-guided synthesis would be a feasible approach to reduce the MW and enhance cell penetration while retaining multivalency for binding. The approach involves in situ synthesis of PPI inhibitors templated by targeted protein surfaces (Fig. 1b). Two reactive small-module compounds are designed to bind side-by-side to a targeted protein surface. Upon binding, the resulting proximity effect would trigger a chemical ligation, producing a covalently conjugated compound that is predicted to be a better PPI inhibitor than either module compound alone. We were also interested in exploring an approach based on bivalent inhibitors for the simultaneous targeting of both a cavity within and the surface of the targeted protein (Fig. 1c). The molecular design of such compounds can be achieved by the covalent linking of two modules with an appropriate spacer. The cavity-binding module should bind into the active pocket in a selective manner and anchor the entire molecule near the cavity, thus allowing for a minimally sized surface module to bind to the flat protein surface. The following sections describe the proof-of-concept studies based upon these hypotheses.

\section{[Insert Figure 1]}

\section{Dendritic Metal Complexes for Protein Surface Recognition}

Antibody-like metal complexes featuring large surface areas and multivalency for protein surface recognition are attractive scaffolds for the development of PPI inhibitors as well as for metal-mediated protein assembly. ${ }^{9} \mathrm{We}^{10}$ and others ${ }^{11}$ have been studying ruthenium(II) tris(bipyiridine) (Ru[bpy $]_{3}$ ) complexes for their potential to serve as protein surface-directed agents. We first investigated a strategy for protein surface binding using a series of dendritic Ru(bpy) $)_{3}$ complexes in which crucial functional groups are located at different positions for recognition of the characteristic surface structure of $\alpha$-chymotrypsin (ChT) ${ }^{10 a}$ The serine protease bovine pancreatic ChT $(\mathrm{p} I \sim 9)$ possesses a number of basic amino acid residues that form a characteristic ring structure around the active site. This positively charged surface is implicated in PPIs with naturally occurring proteinaceous inhibitors. ${ }^{12}$ Based on the structural characteristics of the surface of ChT, we introduced glutamic acid, glutamyl phenylalanine dipeptide, and two phenylalanine residues at the 4 and 4' positions of 2,2'-bipyridine, with 5-amino isophthalic acid serving as a spacer (1-3a; Fig. 2a). The net charge of 1-3a was fixed at -12 , and the complexes ranged from 23-34 $\AA$ in diameter. A superimposition model suggested that 3a was of an appropriate size to cover the active site $\left(\sim 600 \AA^{2}\right)$ while placing the terminal carboxyl groups near the appropriate positively charged residues on the protein surface (Fig. 2b). 
[Insert Figure 2]

The binding affinity of each complex $(10 \mu \mathrm{M})$ to ChT was evaluated by titration, monitoring the change in luminescence at $620 \mathrm{~nm}$ in phosphate buffer at $\mathrm{pH}$ 7.4. Little change in luminescence was observed for compounds $\mathbf{1}$ and $\mathbf{2}$, but the relative luminescence strength of 3a increased upon titration with ChT (Fig. 2c). A simple 1:1 binding model was apparently out of line with the data, whereas a multiple-equilibrium model with 1:1 and 1:2 binding fit well the data set, clearly demonstrating that the association of 3a with ChT involves 1:1 and 1:2 (3a:ChT) complex formation, with low micromolar dissociation constants for each equilibrium step (Fig. 2c). Plausible models for the 1:1 and 1:2 complexes are shown in Figure 2d. Because of the structural features of its octahedral complex, 3a likely possesses two binding sites composed of three isophthalic arms at each position and presumably forms a rod-shaped $\mathrm{Ru}(\mathrm{bpy})_{3}$ complex with two equivalents of ChT.

We also evaluated the ChT inhibition activity of the Ru(bpy) $)_{3}$ complexes using a spectroscopic assay with the chromogenic substrate $N$-benzoyltyrosine- $p$-nitroanilide (BTNA). The proteinaceous soybean trypsin inhibitor (STI, $20 \mathrm{kDa}$ ) is known to bind to ChT, which implies an interfacial surface of $1,600 \AA^{2}$, with a $K_{d}$ value of $1 \times 10^{-7} \mathrm{M}^{12}$ Only an equimolar amount of STI was necessary for complete inhibition of enzyme activity. Although compound $\mathbf{1}$ was completely inactive and $\mathbf{2}$ showed moderate inhibition (Fig. 3a), dendritic compound 3a showed significant inhibitory activity (74 \pm 17\%), which was probably a reflection of its higher affinity for ChT compared with $\mathbf{1}$ and $\mathbf{2}$. The replacement of phenylalanine residues in 3a with lysine methyl esters (3b) markedly reduced the inhibitory activity, suggesting the possibility of electrostatic repulsion between $\mathbf{3 b}$ and the basic surface of ChT. The inactivity of the bipyridine ligand (4) is suggestive of the significance of the integrated effect of functional groups on protein surface binding. Based on these results, we concluded that 3a recognizes the protein surface through complementary interactions between carboxyl groups and the positively charged amino acid residues.

In order to examine the mode of $\mathrm{Ru}(\mathrm{bpy})_{3}$ complex-mediated inhibition of ChT, a Lineweaver-Burk analysis was performed for 3a. The data set fit a noncompetitive model (Fig. 3b), showing that association of $\mathbf{3 a}$ with ChT does not interfere with binding of the substrate to the active site. A computationally generated model (Fig. 3c) suggested that the formation of a ternary complex consisting of 3a:ChT:BTNA is possible. Even when 3a binds to the targeted positively charged surface of ChT, enough space appears to be available for BTNA to bind to the active site. Based on this model, a plausible explanation for the inhibition mechanism suggests that while BTNA still binds to the active site, binding of 3a to the surface of ChT may induce a conformational change in the protein that diminishes its enzymatic activity. This may account for the relatively low inhibitory activity of 3a despite its submicromolar affinity for ChT.

Heteroleptic Ru(bpy) $)_{3}$ complexes were also found to be potent inhibitors of cytochrome c 
reduction and to possess a remarkable ability to penetrate cells. ${ }^{10 \mathrm{~b}}$ In addition, our primary results suggest that simple addition of ferric ion into a mixture of several bipyridine ligands containing various functional groups produces a dynamic combinatorial mixture of $\mathrm{Fe}(\mathrm{bpy})_{3}$ complexes. ${ }^{10 \mathrm{c}}$ Screening of the complex array for inhibition of ChT and thrombin activity resulted in the identification of several potent mixtures for each enzyme. Work aimed at identifying the active species from these mixtures is underway.

In summary, we verified that $\mathrm{Ru}(\mathrm{bpy})_{3}$ complexes provide a useful scaffold for the synthesis of protein surface-directed agents. The size of the complex, the positioning of the functional groups, and the complementary charge distribution were all found to have a considerable effect on the complex's affinity for and inhibition of ChT.

\section{[Insert Figure 3]}

\section{Target-guided Synthesis}

Reducing the molecular weight of a protein-binding agent while retaining its affinity and selectivity for the targeted protein surface is challenging. One strategy for addressing this problem is to synthesize PPI inhibitors on a targeted protein surface in situ by covalently assembling relatively small module compounds (Fig. 1b). The resulting agents should bind more readily to the protein surface than either of the module compounds alone due to the effect of additive binding energies. ${ }^{13}$ The covalent assembly of two ligands on the surface of a protein has been exploited in a number of recent medicinal chemistry studies, the results of which confirm the potential relevance of this approach for synthesizing PPI inhibitors. ${ }^{14-16}$ In order to further evaluate the utility of the covalent assembly, we examined an epoxide-opening reaction between diterpene fusicoccin derivatives and a cysteine-containing pentapeptide, guided by the $14-3-3 \zeta$ protein, for synthesizing natural product-based conjugate molecules. ${ }^{17}$

The 14-3-3 proteins are a family of highly conserved dimeric proteins expressed in all eukaryotic cells. These proteins play critical roles in the regulation of serine/threonine kinase-dependent signaling pathways through phosphorylation-dependent binding to a large number of ligand proteins. ${ }^{18}$ Each 14-3-3 protein monomer possesses an amphipathic groove that binds to a consensus peptide motif containing phosphorylated $\mathrm{T}$ (threonine, Thr) or S (serine, Ser) residues. Recent studies have implicated 14-3-3 proteins in the development of a number of diseases, ${ }^{19}$ suggesting that these proteins have clinical relevance as therapeutic targets.

\section{[Insert Figure 4]}

The fungal phytotoxin fusicoccin A (FC-A; shown in Figure 4a in a ball-stick model with its 
structure shown in Fig. 4b) binds to a hydrophobic cavity adjacent to the phosphopeptide-binding pocket of plant 14-3-3 proteins. This compound forms a stable ternary complex (Fig. 4a) with the phosphopeptide QSYpTV (H-Gln-Ser-Tyr-phosphoThr-Val-OH, shown in Fig. 4a in a stick model), which is derived from the C-terminus of plant $\mathrm{H}^{+}$-ATPase. The formation of the ternary complex is driven by hydrophobic interactions between the FC-A backbone and the isopropyl side chain of the $\mathrm{V}$ residue located at position $\mathrm{i}+1$ relative to the $\mathrm{pT}$ residue. Formation of the ternary complex increases the affinity of both FC-A and the pentapeptide for the 14-3-3 protein by nearly two orders of magnitude. ${ }^{20}$ Thus, we hypothesized that reactive module compounds capable of cooperatively binding to the 14-3-3 groove and triggering covalent bond formation to yield the corresponding conjugate product could be constructed by introducing an appropriate functional group into both FC-A and the peptide. As a result, it should be possible to observe the 14-3-3-template effect, in which the ligation reaction is guided by the protein surface, resulting in enhanced conjugate production.

To test this hypothesis, we chose an epoxide and a thiol as the reactive groups and designed FC-based modules and the peptide fragment accordingly (Fig. 4b). The epoxide was introduced at the 19-position via an appropriate spacer, and the V residue in QSYPTV was replaced with a C residue to prepare the pentapeptide module (QSYPTC) and nonphosphorylated peptide (QSYDC). We then tested the reaction in the presence and absence of 14-3-3 in aqueous solution (Fig. 4c).

We predicted that the FC-module and the C-containing peptide would bind to the 14-3-3 groove in a cooperative manner (Fig. 5a), which would trigger the reaction between the epoxide and the thiol group to form the corresponding conjugate product (Fig. 5b). In order to confirm the cooperative binding of the FC-module and the peptide module to 14-3-3, the binding affinity of QSYpTC for recombinant $14-3-3 \zeta$ in the presence and absence of nonreactive compound $\mathbf{1 0}$ was compared using isothermal titration calorimetry (Fig. 6a). The binding affinity increased by approximately one order of magnitude in the presence of 5 equivalents of $\mathbf{1 0}\left(K_{\mathrm{d}}=0.41\right.$ and $0.046 \mu \mathrm{M}$ in the absence and presence, respectively, of 10), suggesting that the FC derivatives retained the ability to stabilize the interaction between 14-3-3 and the peptide.

\section{[Insert Figure 5]}

The template effect of 14-3-3 upon conjugate formation was then evaluated using HPLC. The FC-based modules (7-9, $300 \mu \mathrm{M})$ were incubated with QSYDC (300 $\mu \mathrm{M})$ in Tris-HCl buffer (pH 9.0) in the presence and absence of $14-3-3 \zeta(300 \mu \mathrm{M})$. The percentage of each conjugate generated $([+]$ $14-3-3 /[-] 14-3-3 \times 100$ ) was calculated based on relative yield (Fig. 6b). In the case of $\mathbf{6}$, in which the epoxide group was directly attached to the C-19 of FC, 14-3-3 reduced conjugate production to 37\% of the control, suggesting that although 6 and QSYDC bound to the 14-3-3 groove, the epoxide did not reach the thiol group in QSYDC, presumably due to restriction imposed by rotation of the amide bond. 
In contrast, formation of conjugate in the reaction involving 7 was enhanced by $14-3-3$ (199\% of the control), demonstrating the template effect of 14-3-3. Compounds 8 and $\mathbf{9}$, which contain longer spacers than 7, reduced the efficiency of conjugate formation (169 and 129\% of the control, respectively), suggesting that appropriate positioning of the epoxide is a key factor in the templated reaction.

\section{[Insert Figure 6]}

In summary, the template effect of the 14-3-3 protein on the chemical ligation of fusicoccin derivatives containing an epoxide group and the pentapeptide QSYDC was confirmed. These results support the potential application of 14-3-3-guided chemical ligation for in situ generation of PPI inhibitors.

\section{Bivalent Enzyme Inhibitors}

a) Module design for inhibitors that simultaneously recognize the active site and surface of Type I geranylgeranyltrasferase (GGTase-I)

Synthetic chemical probes designed as part of a new concept for simultaneously targeting multiple sites on a protein's surface are of interest due to their potential application as site-specific modulators of PPIs. In this section, we discuss a new approach for synthesizing bivalent inhibitors of mammalian type-I geranylgeranyltransferase (GGTase-I) based on the assembly of modules for simultaneous recognition of both the active site and the protein surface (Fig. 1c).

GGTase- $\mathrm{I}^{21}$ is a heterodimeric zinc-containing metalloenzyme and a member of the protein prenyltransferase family. Mammalian GGTase-I is responsible for transferring a C-20 geranylgeranyl group from geranylgeranyl pyrophosphate (GGPP) to a $C$ residue of the carboxy-terminal CAAX tetrapeptide of the target substrate protein, in which AA is an aliphatic dipeptide, and, in most cases, $\mathrm{X}$ is a L or F residue. ${ }^{22,23}$ GGTase-I has garnered considerable attention due to its potential as a new drug target for treatment of cancer ${ }^{24}$ and other diseases, such as smooth muscle hyperplasia ${ }^{25}$ and hepatitis C. ${ }^{26}$

\section{[Insert Figure 7]}

Mammalian GGTase-I consists of a $48 \mathrm{kDa} \alpha$-subunit and a $43 \mathrm{kDa} \beta$-subunit that contains the hydrophobic active pocket. Crystal structures of the ternary complex of GGTase-I bound to the peptide and a GGPP analog revealed that there is a characteristic acidic region on the surface of the $\alpha$-subunit near the entrance to the active pocket. ${ }^{27}$ We therefore applied the concept of designing bivalent inhibitors to simultaneously target both the active site and the acidic surface of GGTase-I (Fig. 7a). 
The active-pocket module should bind in the cavity in a selective manner and should anchor the entire molecule near the pocket, whereas the surface-binding module requires relatively divergent structural features and multiple positively charged groups for the electrostatic interaction with the GGTase-I surface. The inhibitors synthesized in this study consisted of two modules linked by an alkyl spacer; one was the tetrapeptide CVIL module for binding to the active pocket, whereas the other was a 3,4,5-alkoxy substituted benzoyl motif containing three aminoalkyl groups designed to bind to the negatively charged protein surface near the active site (Fig. 7b).

The compounds were screened for inhibition of GGTase-I activity using an enzyme inhibition assay based on fluorescence spectroscopy. Briefly, recombinant GGTase-I was treated with compound in the presence of geranylgeranyl pyrophosphate (GGPP, $5.0 \mu \mathrm{M}$ ) and the environmentally sensitive fluorogenic substrate, $N$-dansyl-GCVIL (DansGCVIL; $1.0 \mu \mathrm{M}$ ) in Tris-HCl buffer (50 mM, $\mathrm{pH}$ 7.5). This substrate increases the fluorescent intensity upon geranylgeranylation at the cysteine thiol group. The fluorescent increase was monitored for $5 \mathrm{~min}$ and the percentage of inhibition was calculated by comparison with the standard slope, which was taken from the reaction in the absence of inhibitors. The bivalent inhibitors effectively blocked GGTase-I activity, and their potency was found to be approximately one order of magnitude and $>150$ times more effective than the tetrapeptide CVIL and methyl benzoate derivatives, respectively, confirming the synergistic effect on enzyme inhibition (Fig. 8a). A comparison of the effects of compounds 11-13 demonstrated that the spacer length affects the inhibitory activity (Fig. 8b). Compound 13 ( $n=3$; "n" refers to the number of carbons in the spacer), which contains a shorter spacer for the C2 unit than does compound $12\left(\mathrm{n}=5, K_{\mathrm{i}}=0.22 \pm\right.$ $0.04 \mu \mathrm{M}$ ), was a slightly less active inhibitor than 12 (for $13, K_{\mathrm{i}}=0.48 \pm 0.11 \mu \mathrm{M}$ ). On the other hand, compound $11(n=11)$, with a spacer length twice as long as that of $\mathbf{1 2}$, dramatically lost its inhibition potency (Fig. 8b). This suggests that longer spacers diminish the affinity of binding to GGTase-I due to entropic disadvantage ${ }^{28}$ and that the length of the spacer for module assembly should be carefully chosen to achieve optimal activity.

[Insert Figure 8]

Kinetic analyses revealed that the bivalent compounds are competitive inhibitors (Fig. 8c), suggesting that the CVIL module anchors the entire molecule to the active site and delivers the other module to the targeted protein surface. Thus, our module assembly approach provides for simultaneous recognition of multiple sites and consequent synergistic inhibition of GGTase-I activity, thereby providing a new approach for designing protein surface-directed PPI inhibitors.

\section{b) Bivalent dual inhibitors that disrupt PPIs of K-Ras and protein prenyltransferases}

Next, we examined the critical question of whether bivalent inhibitors are useful for disrupting 
PPIs. To address this question, we focused on posttranslational modification of the K-Ras-4B protein, which is normally regulated by farnesyltransferase (FTase).

\section{[Insert Figure 9]}

The heterodimeric zinc metalloenzyme FTase is structurally and functionally similar to GGTase-I (Fig. 9). Importantly, the $48 \mathrm{kDa} \alpha$-subunits of both proteins are identical and are products of the same gene. Thus, both FTase and GGTase-I possess a negatively charged area in which a number of acidic amino acids are clustered. ${ }^{29}$ Over the last two decades, these two enzymes have received intense attention as potential clinical targets. ${ }^{30}$ Furthermore, a recent genetic study suggested that dual inhibitors of both enzymes would be promising cancer therapeutic agents. ${ }^{31}$

Human K-Ras4B is the most frequently mutated Ras isoform in cancers. This protein is normally farnesylated by FTase at the thiol group of the C-terminal CVIM sequence (Fig. 10, solid arrows). However, disruption of K-Ras4B farnesylation by FTase inhibitors causes an alternative geranylgeranylation by GGTase-I (Fig. 10, dashed arrows), which enables K-Ras4B to retain full biological activity. ${ }^{32}$ Biological studies ${ }^{29,33}$ have demonstrated that a critical determinant for the unusual geranylgeranylation of K-Ras4B is the characteristic polylysine sequence near the protein's C-terminus. This highly positively charged region is believed to trigger a transient PPI with the acidic surfaces of FTase and GGTase-I through electrostatic interactions. Thus, we predicted that a compound mimicking the C-terminal structure of K-Ras4B would simultaneously bind to the active site and the acidic surface of both FTase and GGTase-I and block the transient PPI, resulting in dual inhibition of the farnesylation and geranylgeranylation of K-Ras4B.

\section{[Insert Figure 10]}

To test this hypothesis and to evaluate the disruption of the PPI between K-Ras4B and FTase and GGTase-I, we first set up a modified in vitro assay system using a dansylated oligopeptide truncated from the K-Ras-4B C-terminal sequence (KKKKKKSK(Dans)TKCVIM, Fig. 11). We then designed the bivalent compounds based on the C-terminal structural features of K-Ras4B. For designing the active-site module, we employed a strategy similar to that described in the previous section for design of the GGTase-I inhibitors. Namely, we initially chose the CVIM tetrapeptide to ensure that the module would bind to the FTase active site. To mimic the $(\mathrm{K})_{6}$ region, we used a gallate scaffold in which the same number of primary amino groups were introduced using branched alkyl amines. Two modules were covalently linked via an alkyl spacer to produce compound $\mathbf{1 5}$. We anticipated that compound 15 would suppress the farnesylation of the K-Ras4B model peptide much more effectively than CVIM alone, as $\mathbf{1 5}$ features the additional module that disrupts the interaction between the acidic 
surface of FTase and the positively charged area of the model peptide, a module which CVIM does not contain.

[Insert Figure 11]

As shown in Figure 12a, 15 exhibited remarkable inhibition of FTase activity $\left(K_{\mathrm{i}}=0.005 \mu \mathrm{M}\right)$ and was $>200$ times more effective than CVIM $\left(K_{\mathrm{i}}=1.10 \mu \mathrm{M}\right){ }^{34}$ In addition, a Lineweaver-Burk analysis shows that the mode of inhibition by $\mathbf{1 5}$ is competitive. ${ }^{34}$ These results clearly indicate that the compound binds to the active site, delivers the minimally sized surface module to the acidic protein surface, and disrupts the interaction between the substrate and the protein surface.

We then tested $\mathbf{1 5}$ for inhibition of the geranylgeranylation of the K-Ras4B model peptide (Fig. 12a). Alone, CVIM inhibited GGTase-I activity only moderately $\left(K_{\mathrm{i}}=6.69 \mu \mathrm{M}\right)$, which is not surprising because CVIM is not the sequence that is preferably recognized by the GGTase-I active pocket. In contrast, compound $\mathbf{1 5}$ significantly suppressed geranylgeranylation of the model peptide ( $K_{\mathrm{i}}=0.344 \mu \mathrm{M}$ ), demonstrating that by attaching the gallate module, the ineffective CVIM peptide is converted into a reasonably effective GGTase-I inhibitor.

We also evaluated FTase inhibition using structure-activity relationship analysis (Fig. 12b). Whereas replacement of the alkyl spacer in $\mathbf{1 5}$ by an ethylene glycol chain had only a minimal effect, reducing the number of amino groups in the gallate module by half diminished the activity (as seen with compound 17). Furthermore, replacement of the amino groups in $\mathbf{1 7}$ with carboxylate groups dramatically reduced the activity, confirming that the gallate module is involved in the electrostatic interaction with the acidic surface of FTase. Most importantly, only the gallate module was found to be completely inactive, even at high concentrations (>100 $\mu \mathrm{M})$. This confirms that it is the anchoring effect provided by the CVIM module that enables this small and weak surface module to both disrupt PPIs and function as a dual inhibitor of FTase and GGTase-I activity.

\section{[Insert Figure 12]}

To improve the cell-based activity of the bivalent dual inhibitors, we tested the effect of peptidomimetic modification of the CVIM module. ${ }^{35}$ Fluorescence imaging analysis revealed that introducing a peptidomimetic FTI-249 ${ }^{36}$ for the active site module (as seen in compound 19, Fig. 13) enhanced cell penetration. A cell-based evaluation demonstrated that peptidomimetic $\mathbf{1 9}$ at a concentration of $100 \mu \mathrm{M}$ inhibited HDJ-2 (a human $40 \mathrm{kDa}$ heat shock protein) processing in cells, indicating that this peptidomimetic modification improves cell penetration, thus enhancing the whole-cell activity of the bivalent compounds. ${ }^{35 a}$ Further modification of the surface module by replacement of amino groups with guanydyl groups also improved cell-based activity, resulting in a 
compound exhibiting submicromolar activity in cells. ${ }^{35 b}$ Further evaluation of the intracellular dual inhibition activity of this compound is underway in our laboratory.

[Insert Figure 13]

In summary, we used a module assembly approach to design bivalent enzyme inhibitors by covalently linking the active-pocket and surface modules with an appropriate spacer. The resulting compounds significantly inhibited model transient PPIs. Peptidomimetic modification improved the whole-cell activity of the compounds. The anchoring strategy discussed here may lead to a general approach for designing selective and cell-penetrating mid-sized PPI inhibitors as well as dual enzyme inhibitors targeting exterior protein surfaces.

\section{Conclusions}

Based on the simple concept of modular assembly of mid-sized molecules, we studied several methodologies for constructing multivalent agents that are capable of binding to protein surfaces. Our results from the study of $\mathrm{Ru}(\mathrm{bpy})_{3}$ support the potential application of transition metal complexes for further development of PPI inhibitors. These structurally tuneable scaffolds may serve as useful tools in structure-activity relationship investigations of protein surface-directed agents. The moderate inhibitory activity of homoleptic Ru(bpy) $)_{3}$ against ChT needs to be improved. Dynamic combinatorial libraries containing homo- and heteroleptic metal complexes may be beneficial in searches for the best combination of ligands necessary for specific interaction with targeted protein surfaces.

Although target-guided inhibitor synthesis is a challenging approach for the development of PPI inhibitors, our initial studies involving 14-3-3 suggest that module-conjugate synthesis templated by a target protein can be achieved. Of course, critical issues remain to be resolved, for instance, improving the reaction efficiency and inhibition potency of the resulting conjugate and determining how to overcome diffusion problems. These questions will need to be addressed during further development of the strategy.

Our results prove that designing bivalent enzyme inhibitors is a promising strategy that allows for 1) exploiting minimally sized surface modules that are weak binders by themselves, 2) disrupting transient PPIs, and 3) dual inhibition of enzymes such as FTase and GGTase-I. We expect that this methodology will be applicable to the inhibition of other PPIs if the targeted proteins possess cavities or an active pocket. In addition, the concept of simultaneous binding to both the active site and protein surface may lead to a general strategy for designing dual enzyme inhibitors targeting common or similar protein surface structures in addition to the traditionally targeted active pockets. Development of synthetic inhibitors of PPIs will certainly require more work to assess their relevance and feasibility. However, we believe that focusing on mid-sized molecules will help us to move toward a new 
paradigm and define the pharmacological properties that are necessary for a synthetic compound to be a potential drug for this class of targets.

\section{Acknowledgements}

The work described here was performed in the Institute of Scientific and Industrial Research, Osaka University. I would like to thank many co-workers for their contributions. I would especially like to acknowledge Dr. Shinnosuke Machida, Michiko Takahashi, Akie Kawamura, Toshio Maki, Kakeru Usuba, and Ritsuko Satoh for their dedication and hard work. I would also like to thank Prof. Nobuo Kato (Osaka University), Prof. Andrew Hamilton (University of Oxford), Prof. Said Sebti (University of South Florida), and Ms. Michelle Blaskovich (University of South Florida) for their helpful discussions. This work was supported by the Japan Society for the Promotion of Science, the Takeda Science Foundation, the Naito Foundation, the Suzuken Memorial Foundation, the Eisai Research Foundation, and the Hayashi Memorial Foundation.

\section{REFERENCES}

[1] (a) J. Wells, C. L. McClendon, Nature, 2007, 450, 1001; (b) A. Whitty, G. Kumaravel, Nature Chem. Biol. 2006, 2, 112.

[2] M. P. H. Stumpf, T. Thorne, E. de Silva, R. Stewart, H. J. An, M. Lappe, C. Wiuf, Proc. Natl. Acad. Sci. USA 2008, 105, 6959.

[3] T. Clackson, J. A. Wells, Science 1995, 267, 383.

[4] (a) G. M. Lee, C. S. Craik, Science 2009, 324, 213; (b) K. A. Reynolds, R. N. McLaughlin, R. Ranganathan, Cell 2011, 147, 1564.

[5] K. McMillan, M. Adler, D. S. Auld, J. J. Baldwin, E. Blasko, L. J. Browne, D. Chelsky, D. Davey, R. E. Dolle, K. A. Eagen, S. Erickson, R. I. Feldman, C. B. Glaser, C. Mallari, M. M. Morrissey, M. H. J. Ohlmeyer, G. Pan, J. F. Parkinson, G. B. Phillips, M. A. Polokoff, N. H. Sigal, R. Vergona, M. Whitlow, T. A. Young, J. J. Devlin, Proc. Natl. Acad. Sci. USA 2000, 95, 1506.

[6] (a) C. Meier, S. Cairns-Smith, U. Schulze, Drug Discov. Today 2013, 18, 607; (b) A. Mullard, Nature Rev. Drug Discov. 2012, 11, 173; (c) M. C. Smith, J. E. Gestwicki, Expert Rev. Mol. Med. 2012, 14, e16; (d) X. Morelli, R. Bourgeas, P. Roche, Curr. Opin. Chem. Biol. 2011, 15, 475; (e) O. Sperandio, C. H. Reynes, A-C. Camproux, B. O. Villoutreix, Drug Discov. Today 2010, 15, 220; (f) M. R. Arkin, A. Whitty, Curr. Opin. Chem. Biol. 2009, 13, 284.

[7] J. Kotz, SciBX 2012, Jan. 26, 1.

[8] (a) Y. Tanaka, C. J. Hipolito, A. D. Maturana, K. Ito, T. Kuroda, T. Higuchi, T. Katoh, H. E. Kato, M. Hattori, K. Kumazaki, T. Tsukazaki, R. Ishitani, H. Suga, O. Nureki, Nature 2013, 496, 247;

(b) C. Heinis, T. Rutherford, S. Freund, G. Winter, Nature Chem. Biol. 2009, 5, 501. 
[9] S. Burazerovic, J. Gradinaru, J. Pierron, and T. R. Ward, Angew. Chem. Int. Ed. 2007, 46, 5510.

[10] (a) J. Ohkanda, R. Satoh, N. Kato, Chem. Commun. 2009, 6949; (b) Y. Yamaguchi, N. Kato, H. Azuma, T. Nagasaki, J. Ohkanda, Bioorg. Med. Chem. Lett. 2012, 22, 2354. (c) K. Fujii, N. Kato, J. Ohkanda, unpublished results.

[11] (a) H. Takashima, S. Shinkai, and I. Hamachi, Chem. Commun. 1999, 2345; (b) M. H. Filby, J. Muldoon, S. Dabb, N. C. Fletcher, A. E. Ashcroft, A. J. Wilson, Chem. Commun. 2011, 559.

[12] C. Capasso, M. Rizzi, E. Menegatti, P. Ascenzi, M. Bolognesi, J. Mol. Recognit. 1997, 10, 26.

[13] W. P. Jencks, Proc. Natl. Acad. Sci. USA 1981, 78, 4046.

[14] D. A. Erlanson, A. C. Braisted, D. R. Raphael, M. Randal, R. M. Stroud, E. M. Gordon, J. A. Wells, Proc. Nat. Acad. Sci. USA 2000, 97, 9367.

[15] G. E. de Kloe, D. Bailey, R. Leurs, L. J. P. de Esch, Drug Discov. Today 2009, 14, 630 and the references cited therein.

[16] a) D. Antonow, Drug Discov. Today 2010, 15, 801; b) X. Hu, R. Manetsch, Chem. Soc. Rev. 2010, 39, 1316.

[17] T. Maki, A. Kawamura, N. Kato, J. Ohkanda, Mol. BioSyst. 2013, 9, 940.

[18] A. K. Gardino, M. B. Yaffe, Semin. Cell Dev. Biol. 2011, 22, 688 and the references cited therein.

[19] a) H. Hermeking, Nat. Rev. Cancer 2003, 3, 931; b) J. Zhao, C. L. Meyerkord, Y. Du, F. R. Khuri, H. Fu, Semin. Cell Dev. Biol. 2011, 22, 705.

[20] M. Wüurtele, C. J. Ottmann, A. Wittinghofer, C. Oecking, EMBO J. 2003, 22, 987.

[21] M. C. Seabra, Y. Reiss, P. J. Casey, M. S. Brown, Cell 1991, 65, 429.

[22] W. W. Epstein, D. Lever, L. M. Leining, E. Bruenger, H. C. Rilling, Proc. Nat. Acad. Sci. USA. 1991, 88, 9668.

[23] P. J. Casey, J. Lipid Res. 1992, 33, 1731.

[24] (a) J. Sun, J. Ohkanda, D. Coppola, H. Yin, M. Kothare, B. Busciglio, A. D. Hamilton, S. M. Sebti, Cancer Res. 2003, 63, 8922; (b) Y. K. Peterson, P. Kelly, C. A. Weinbaum, P. J. Casey, J. Biol. Chem. 2006, 281, 12445; (c) H. Peng, D. Carrico, V. Thai, M. A. Blaskovich, C. Bucher, E. E. Pusateri, S. M. Sebti, A. D. Hamilton, Org. Biomol. Chem. 2006, 4, 1768; (d) A. M. Sjogren, K. M. Andersson, M. Liu, B. A. Cutts, C. Karlsson, A. M. Wahlstrom, M. Dalin, C. Weinbaum, P. J. Casey, A. Tarkowski, B. Swolin, S. G. Young, M. O. Bergo, J. Clin. Invest. 2007, 117, 1294; (e) S. Castellano, H. D. G. Fiji, S. S. Kinderman, M.Watanabe, P. D. Leon, F. Tamanoi, O. Kwon, J. Am. Chem. Soc. 2007, 129, 5843.

[25] B. S. Zuckerbraun, J. E. Barbato, A. Hamilton, S. Sebti, E. J. Tzeng, Surg. Res. 2005, 124, 256.

[26] J. Ye, C. Wang, J. Rhea Sumpter, M. S. Brown, J. L. Goldstein, J. Michael Gale, Proc. Nat. Acad. Sci. USA. 2003, 100, 15865.

[27] (a) K. L. Terry, P. J. Casey, L. S. Beese, Biochemistry 2006, 45, 9746; (b) T. S. Reid, S. B. Long, L. S. Beese, Biochemistry 2004, 43, 9000; (c) J. S. Taylor, T. S. Reid, K. L. Terry, P. J. Casey, L. 
S. Beese, EMBO J. 2003, 22, 5963.

[28] D. K. Srivastava, K. M. Jude, A. L. Banerjee, M. Haldar, S. Manokaran, J. Kooren, S. Mallik, D. W. Christianson, J. Am. Chem. Soc. 2007, 129, 5528.

[29] S. B. Long, P. J. Casey, L. S. Beese, Structure 2000, 8, 209.

[30] (a) A. Kazi, A. Carie, M. A. Blaskovich, C. Bucher, V. Thai, S. Moulder, H. Peng, D. Carrico, E. Pusateri, W. J. Pledger, N. Berndt, A. D. Hamilton, S. M. Sebti, Mol. Cell. Biol. 2009, 29, 2254; (b) M. H. Gelb, L. Brunsveld, C. A. Hrycyna, S. Michaelis, F. Tamanoi, W. C. V. Boorhis, H. Waldmann, Nat. Chem. Biol. 2006, 2, 518.

[31] M. Liu, A-K. M. Sjogren, C. Karlsson, M. X. Ibrahim, K. M. E. Andersson, F. J. Olofsson, A. M. Wahlstrom, M. Dalin, H. Yu, Z. Chem, S. H. Yang, S. G. Young, M. O. Bergo, Proc. Natl. Acad. Sci. USA 2010, 107, 6471.

[32] (a) D. B. Whyte, P. Kirschmeier, T. N. Hockenberry, I. Nunez-Oliva, L. James, J. J. Catino, W. R. Bishop, J. Pai, J. Biol. Chem. 1997, 272, 14459; (b) G. L. James, J. L. Goldstein, M. S. Brown, J. Biol. Chem. 1995, 270, 6221.

[33] (a) G. L. James, J. L. Goldstein, M. S. Brown, J. Biol. Chem. 1995, 270, 6221; (b) J. J. Fiordalisi, R. L. Johnson II, C. A. Weinbaum, K. Sakabe, Z. Chen, P. J. Casey, A. D. Cox, J. Biol. Chem. 2003, 278, 41718.

[34] S. Machida, N. Kato, K. Harada, J. Ohkanda, J. Am. Chem. Soc. 2011, 133, 953.

[35] (a) S. Machida, M. Tsubamoto, N. Kato, K. Harada, J. Ohkanda, Bioorg. Med. Chem. 2013, 21, 4004; (b) M. Tsubamoto, N. Kato, J. Ohkanda, 2013, unpublished results.

[36] A. Vogt, Y. Qian, M. A. Blaskovich, R. D. Fossum, A. D. Hamilton, S. M. Sebti, J. Biol. Chem. 1995, 270, 660 . 


\section{Biographical sketch}

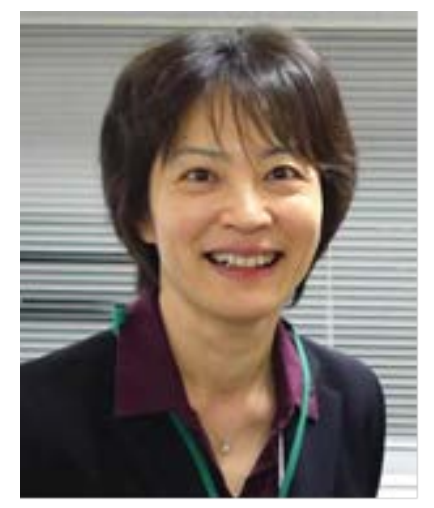

Junko Ohkanda earned an MSc. from Ochanomizu University, and received her Ph. D. from The University of Tokyo in 1990 and 1996, respectively. After serving as a Research Scientist at Richo Corp in 1990 and as a Research Associate at Seikei University from 1991-1997, she moved to the US in 1998 for her postdoctoral training with Professor Andrew Hamilton at Yale University. In 2004, after spending one year as a Research Scientist at Achillion Pharmaceuticals, Inc. in Connecticut, she returned to Japan, and was first appointed as a Lecturer at Tokyo Gakugei University, and was later promoted to the Associate Professor at Osaka University in 2005. In April 2013, she relocated to Institute for Chemical Research, Kyoto University and joined Professor Motonari Uesugi's group as an Associate Professor. Her research interests include bioorganic medicinal chemistry as well as chemical biology, in which she focuses on structure-based design of mid-sized synthetic agents using peptides and natural products for disrupting and detecting protein-protein interactions. 


\section{Graphical abstract:}

In an effort to explore new methodologies that are applicable to the design of synthetic inhibitors of protein-protein interactions, we examined a strategy based on the assembly of small module compounds to create multivalent mid-sized agents. Three particular approaches for assembling modules, metal-chelating, covalent chemical ligation templated by a targeted protein, and bivalent inhibitor design for simultaneous targeting of the cavity and surface, are described. These strategies were shown to be useful for synthesizing minimally sized synthetic agents for targeting PPIs and may enable development of agents that are applicable to inhibition of intracellular PPIs.

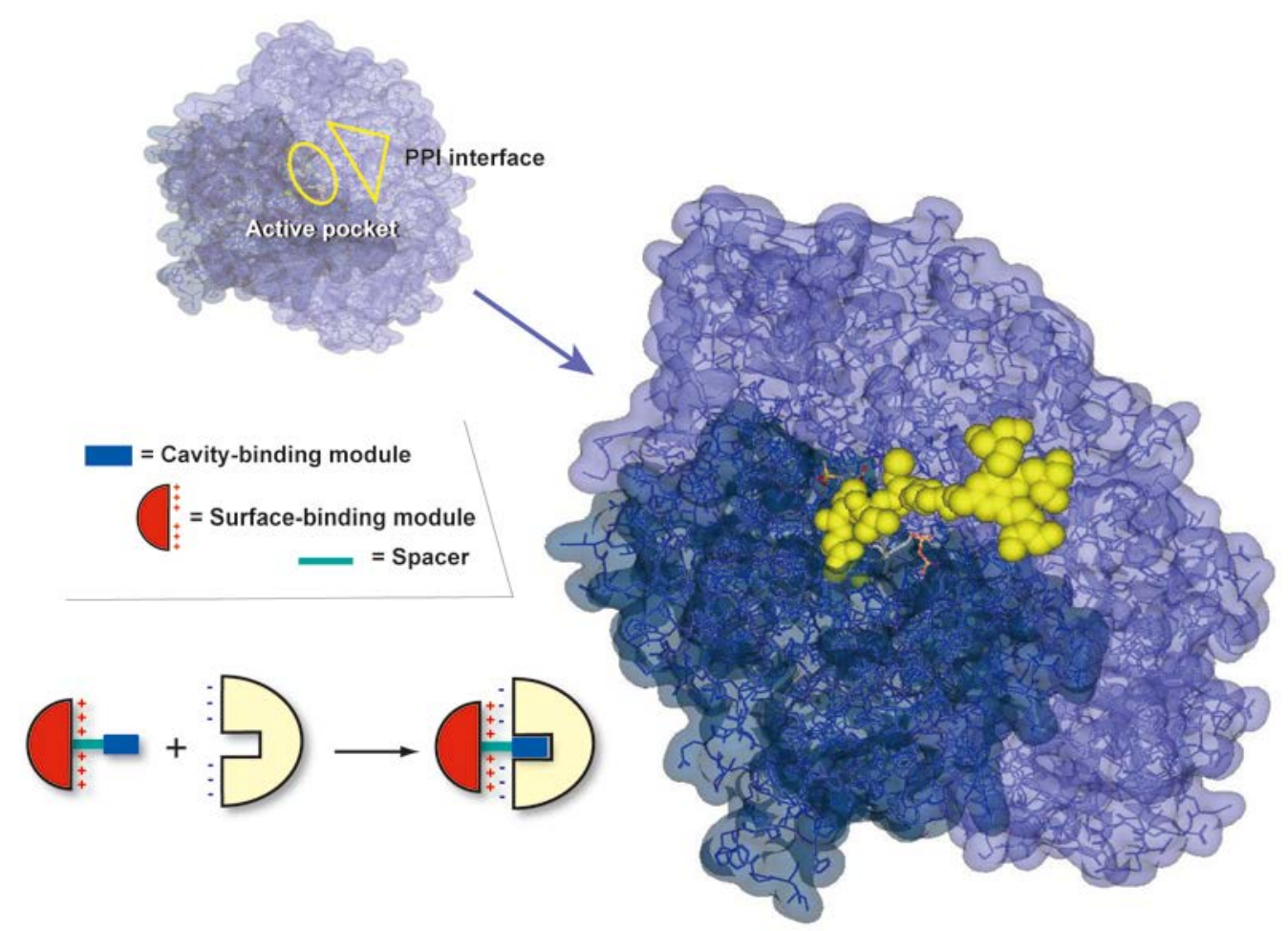


a) Metal Complex-based Library

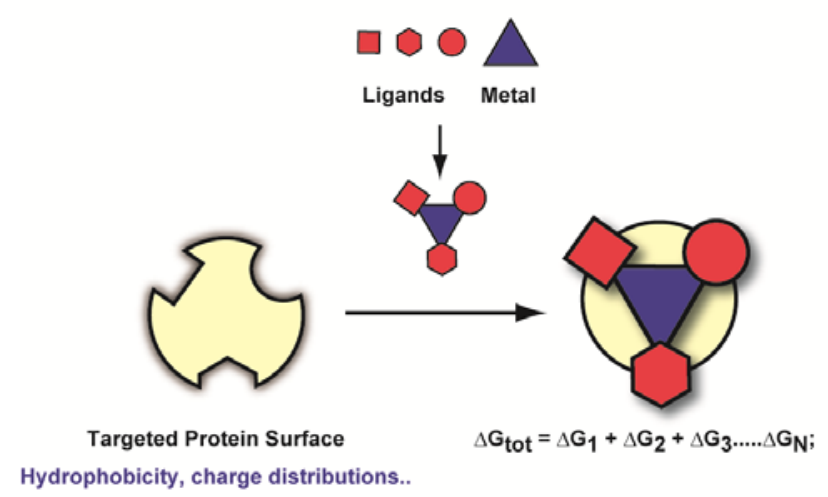

b) Target-guided Synthesis

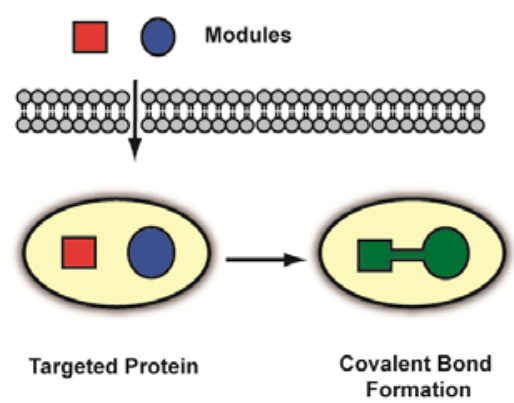

c) Anchoring
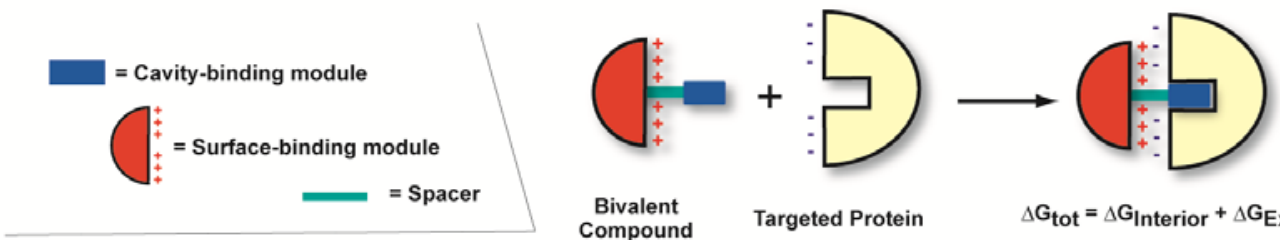

$\Delta \mathbf{G}_{\text {tot }}=\Delta \mathbf{G}_{\text {Interior }}+\Delta \mathbf{G}_{\text {Exterior }}+\Delta \mathbf{G}_{\text {Spacer }}$

Fig. 1. Schematic illustration of strategies based on the module assembly approach. 
a)

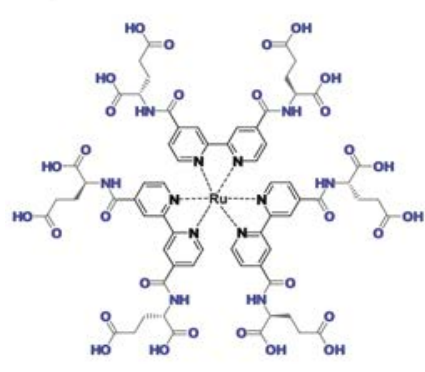

1: Glu (-12)

b)

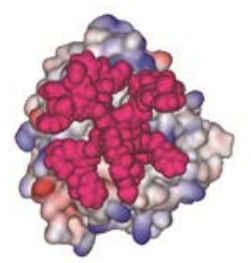

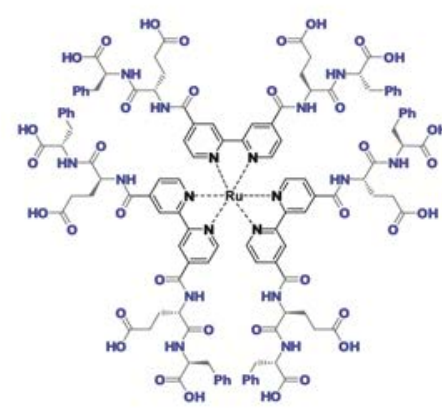

2: GluPhe (-12)

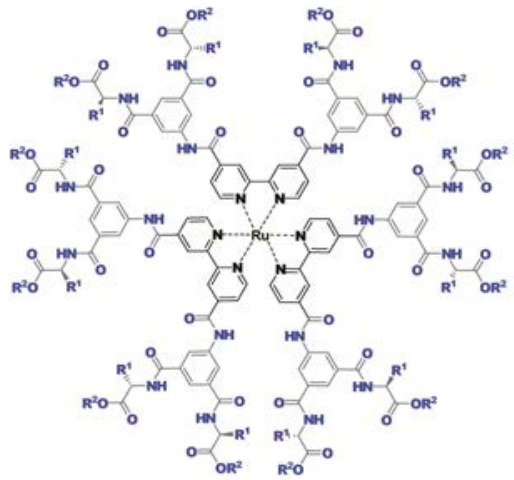

3. $\mathrm{R}^{1}$ $\mathrm{R}^{2}$ iPh-Phe (-12)

b: $\left(\mathrm{CH}_{2}\right)_{4} \mathrm{NH}_{2} \quad$ Me iPh-Lys (+12) c)

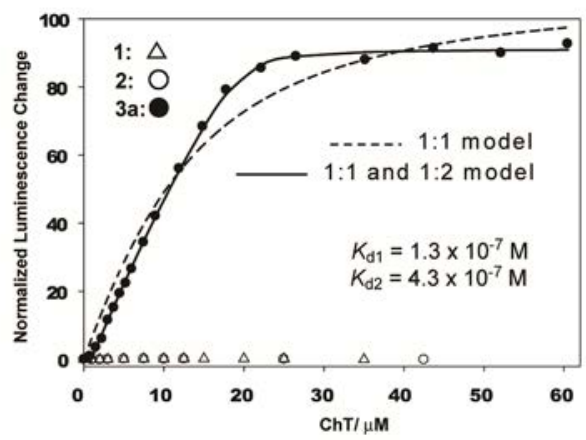

d)

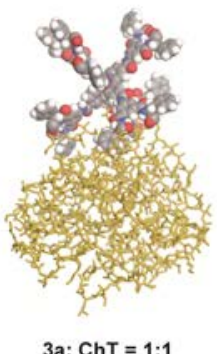

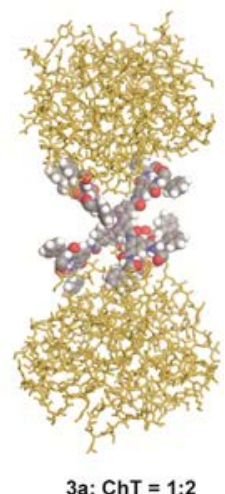

Fig. 2. (a) Structure of Ru(bpy) $)_{3}$ complexes 1-3. (b) A superimposed model of 3a (CPK) and ChT. (c) Titration curves for $10 \mu \mathrm{M} \mathrm{1,2}$, and 3a. (d) A plausible model for 1:1 and 1:2 binding of 3a (CPK) to ChT (stick). 
a)

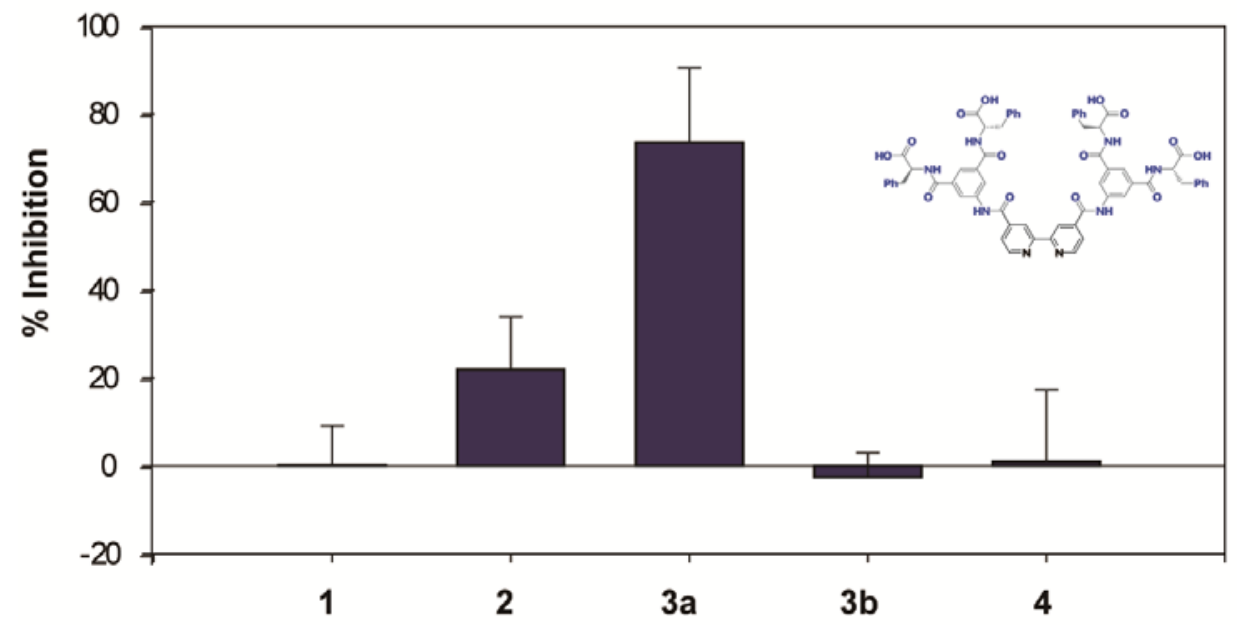

b)

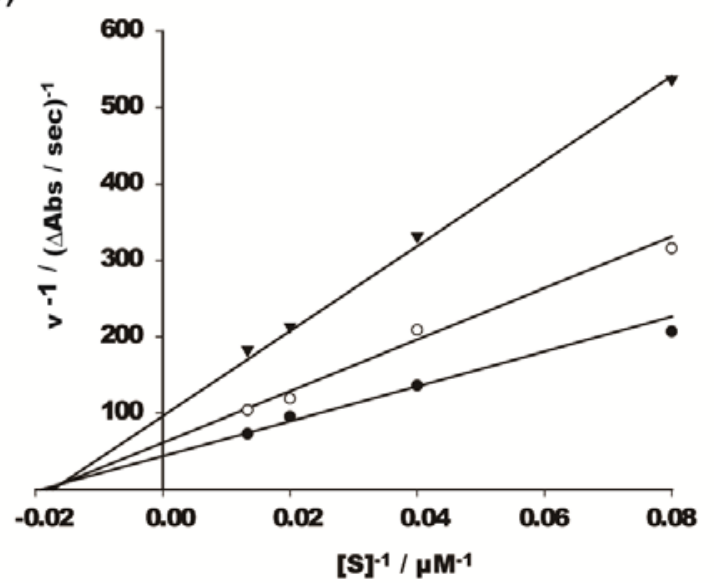

c)

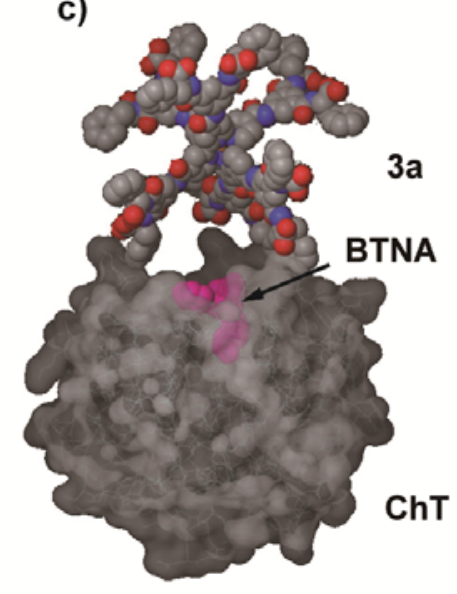

Fig. 3. (a) Inhibition of ChT by $\mathrm{Ru}(\mathrm{bpy})_{3}$ complexes 1-3 and ligand $4(75 \mu \mathrm{M})$. Inhibition assays were performed using $N$-benzoyltyrosine-p-nitroanilide (BNTA, $100 \mu \mathrm{M}$ ). (b) Kinetic analysis of the inhibition of ChT by $3 \mathbf{a}(0(\bullet), 10(\circ)$, and $30(\boldsymbol{\nabla}) \mu \mathrm{M})$. (c) A plausible model for the ternary complex of ChT bound to 3a (CPK) and BTNA. 
a)

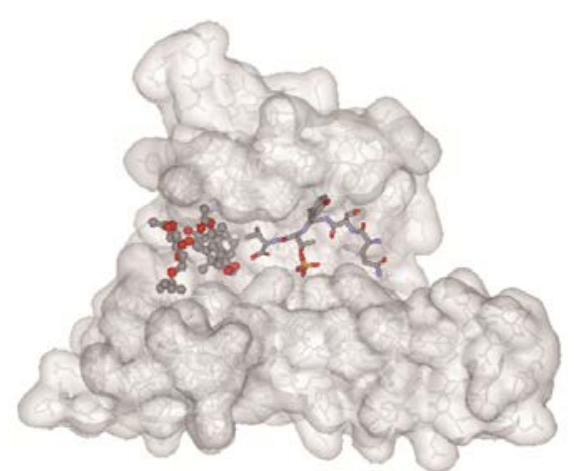

b)

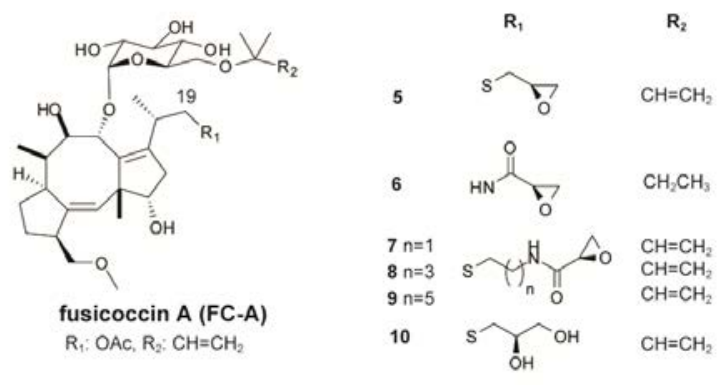

c)
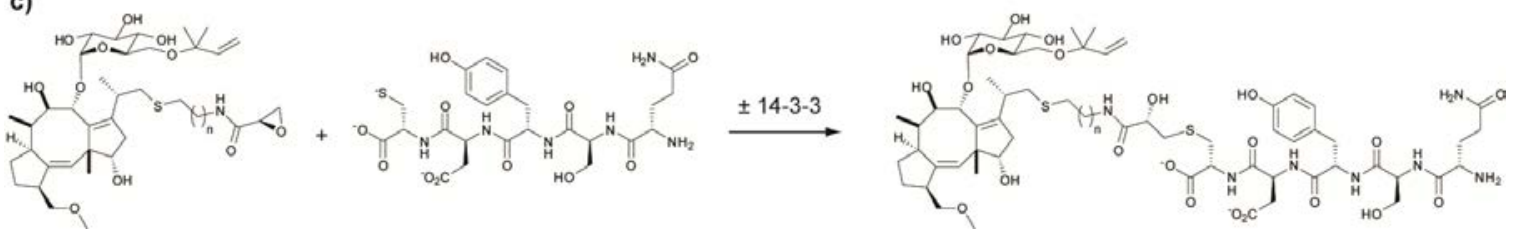

Fig. 4. (a) Crystal structure of the ternary complex of 14-3-3, fusicoccin A (FC-A) (ball and stick), and the phosphopeptide QSYpTV (stick). PDB ID = 1of9. (b) Chemical structure of FC-A and FC-based modules (1-6). (c) Intended chemical ligation templated by 14-3-3. 


\section{a)}

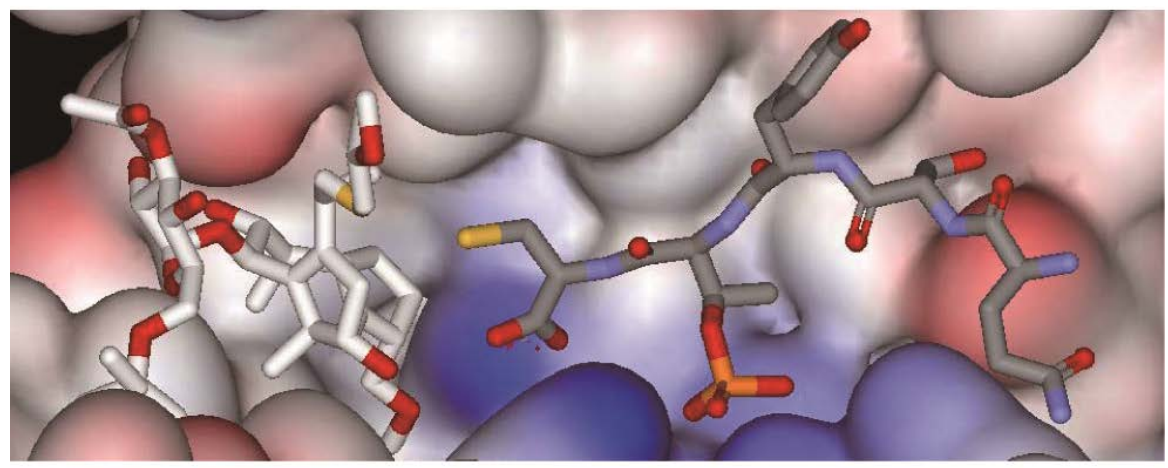

b)

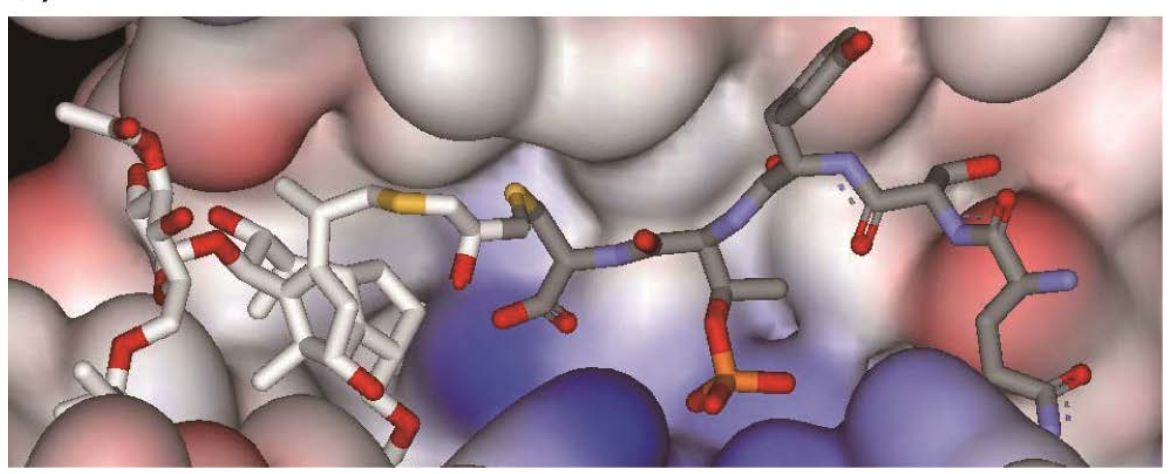

Fig. 5. Hypothetical model of epoxide-containing fusicoccin (5: white stick) and pentapeptide fragment QSYPTC (gray stick) bound to 14-3-3. (a) Compound 5 and QSYpTC bind to the 14-3-3 groove, and (b) the thiol group of QSYpTC reacts with the epoxide moiety of $\mathbf{5}$ to form the conjugate product. 
a)
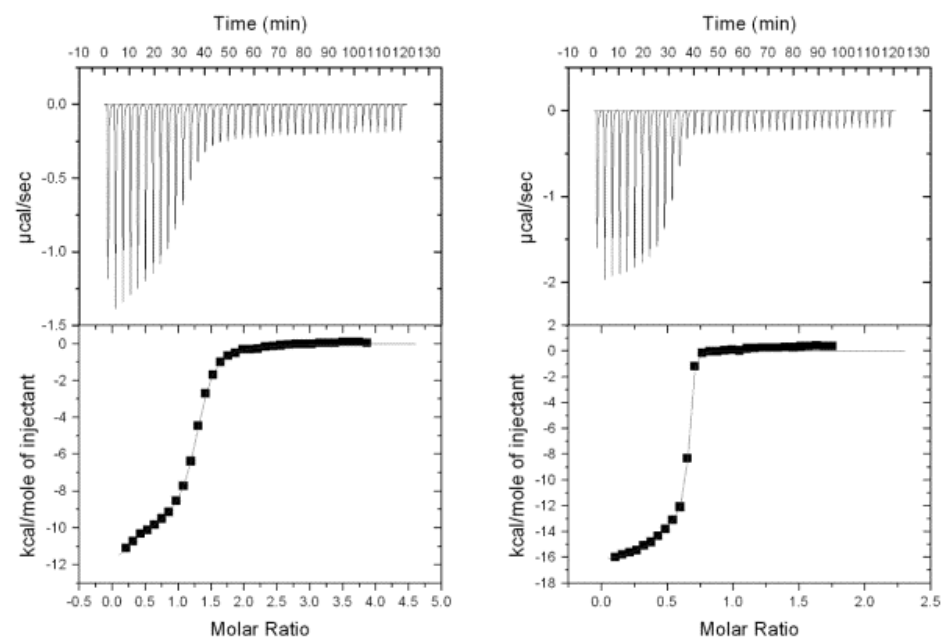

b)

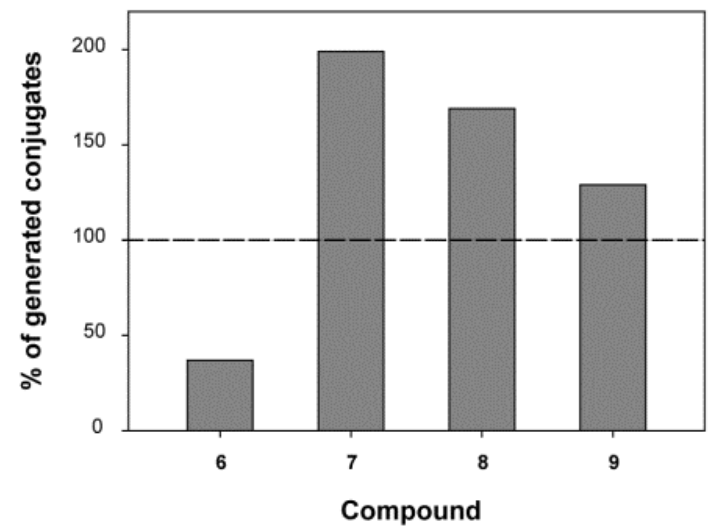

Fig. 6. (a) Isothermal titration calorimetry measurements. Left: experiment in which QSYPTC was

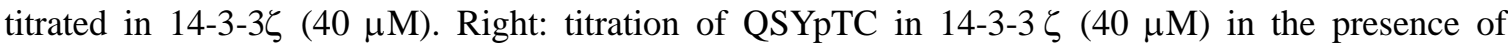
compound $10(200 \mu \mathrm{M})$. (b) Relative yield of conjugates generated by the ligation reaction between compounds 6-9 $(300 \mu \mathrm{M})$ and the QSYDC pentapeptide $(300 \mu \mathrm{M})$ in the presence and absence of

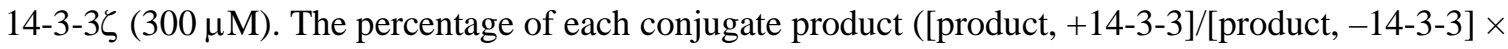
100) was calculated based on the corresponding HPLC peak areas. 
a)

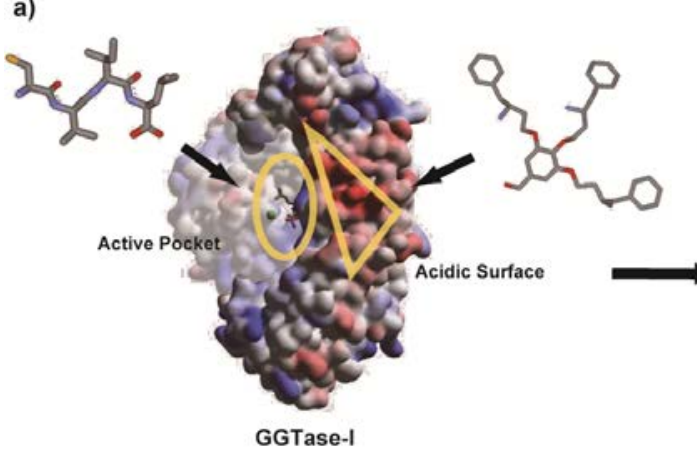

b)

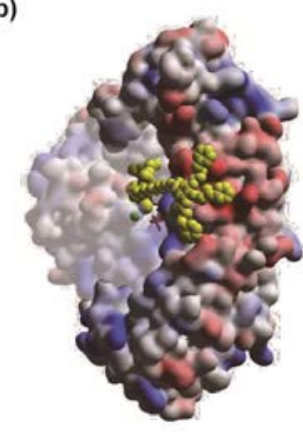

Fig. 7. (a) Schematic representation of the module design of bivalent GGTase-I inhibitors. (b) A superimposed model of $\mathbf{1 1}$ with the crystal structure of GGTase-I. 
a)

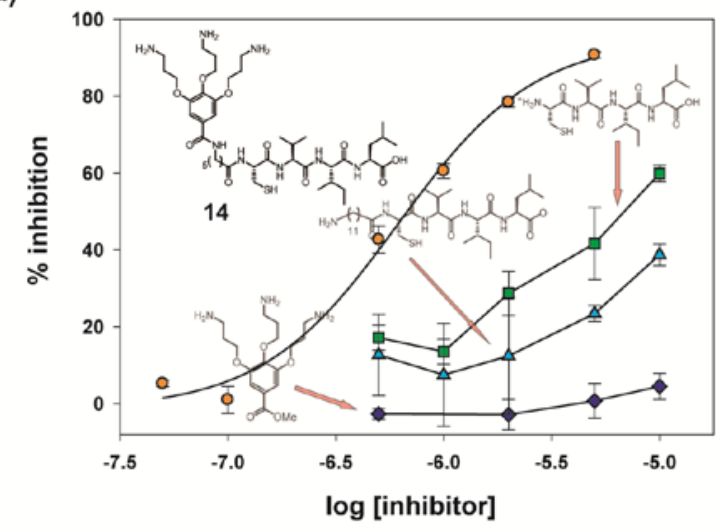

b)

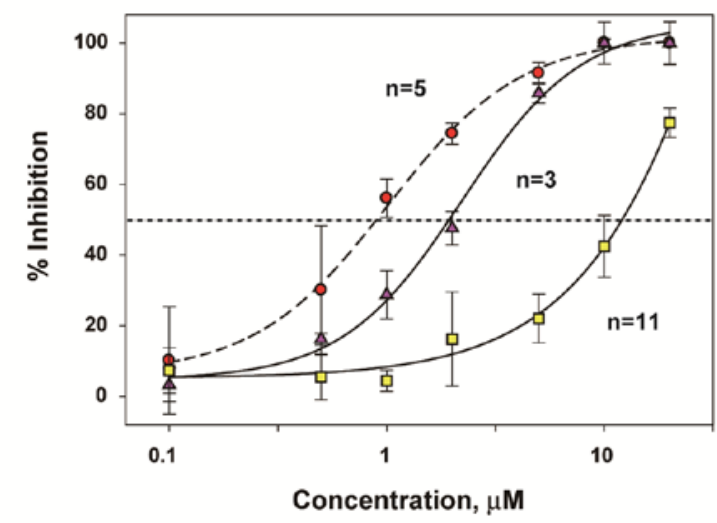

c)

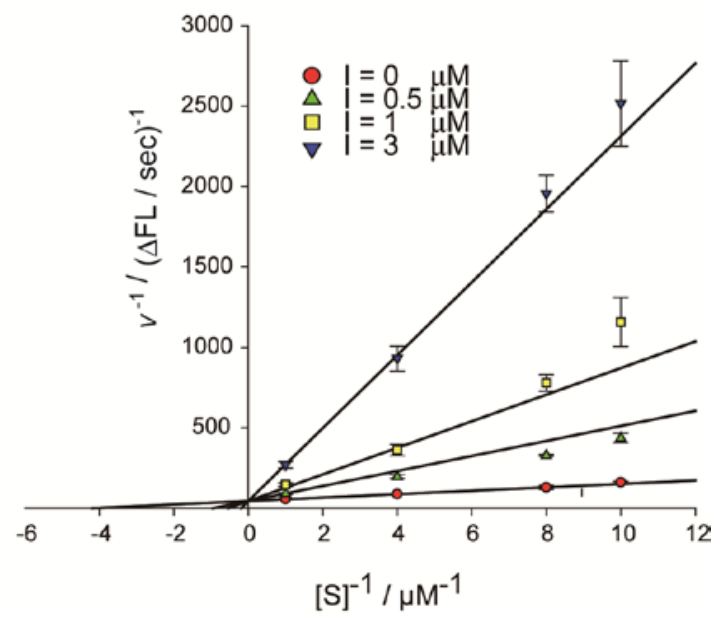

Fig. 8. (a) Dose-response curves for the modules CVIL, gallate derivative, spacer-attached CVIL, and compound 14 plotted against percent inhibition of GGTase-I activity. (b) Dose-response curves for the bivalent compounds with variable-length spacers (11-13). (c) Kinetic analysis of the inhibition of GGTase-I activity by bivalent compound 12. 


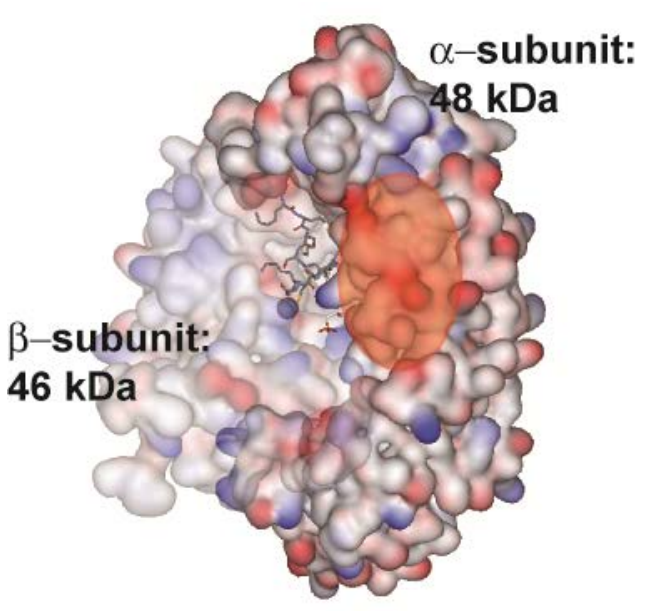

FTase

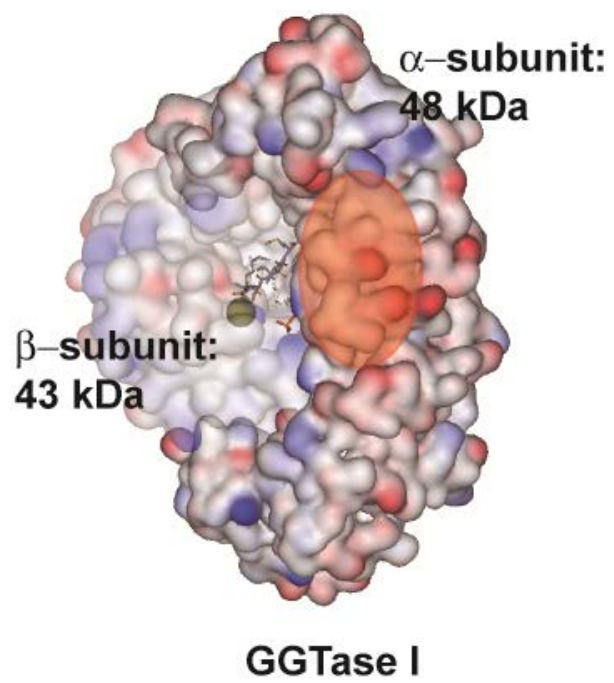

Fig. 9. Crystal structures of the ternary complexes of mammalian FTase (1D8D) and GGTase I (1N4Q) bound to the peptide substrate and prenyldiphosphate analogs. The acidic areas of the $\alpha$-subunits are highlighted with a shaded circle. 


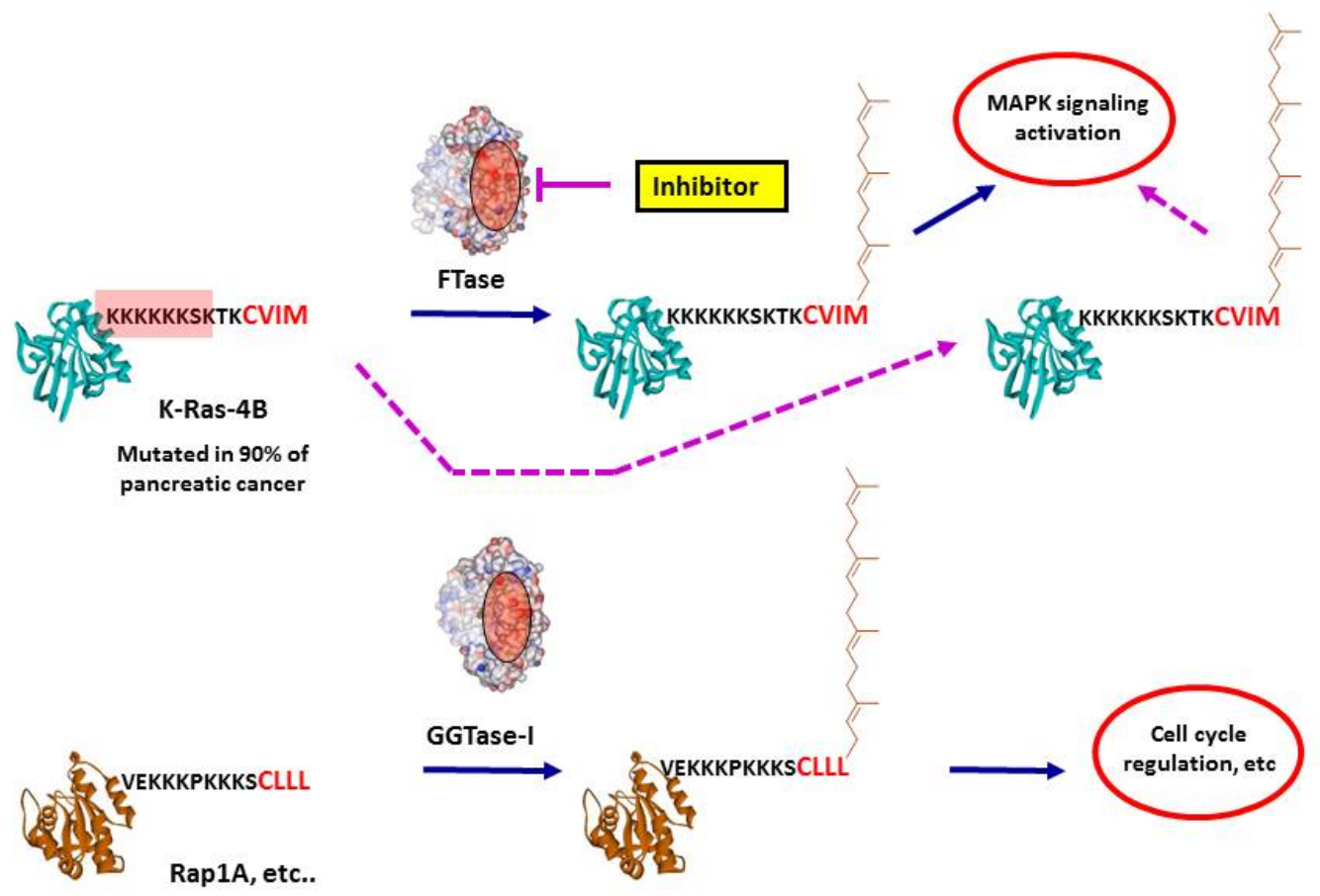

Fig. 10. Schematic representation of the prenylation pathways of K-Ras-4B proteins: normal farnesylation (solid arrows) and unusual geranylgeranylation (dashed arrows) mediated by FTase and GGTase-I, respectively. Acidic surfaces of FTase and GGTase-I are highlighted with shaded circles. 


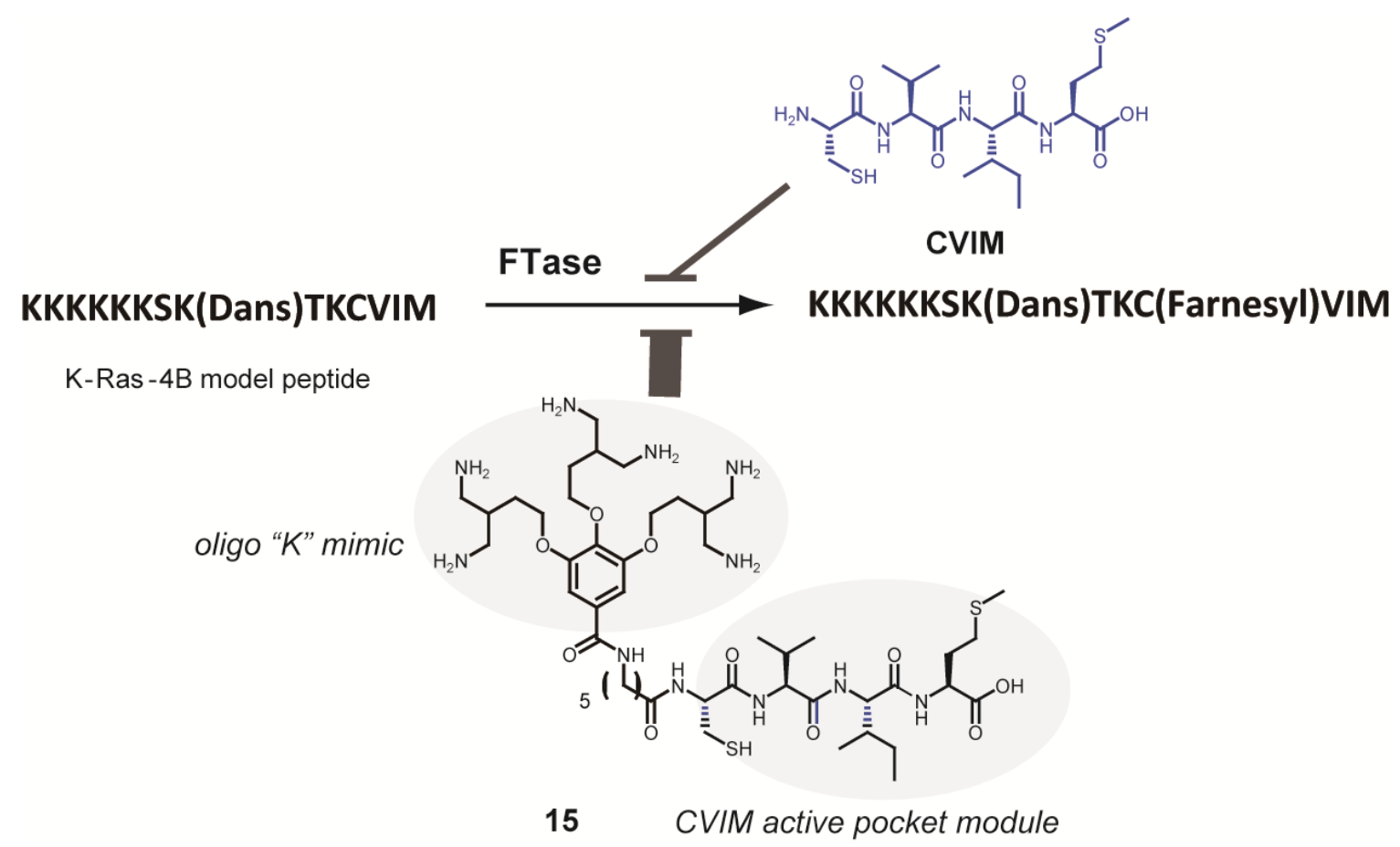

Fig. 11. Chemical structures of bivalent inhibitors of K-Ras-4B prenylation. 
a)

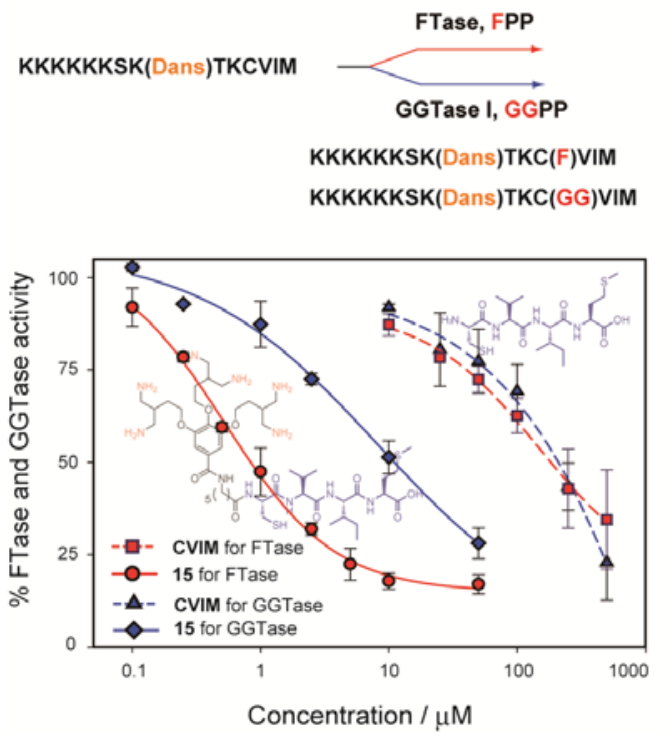

b)

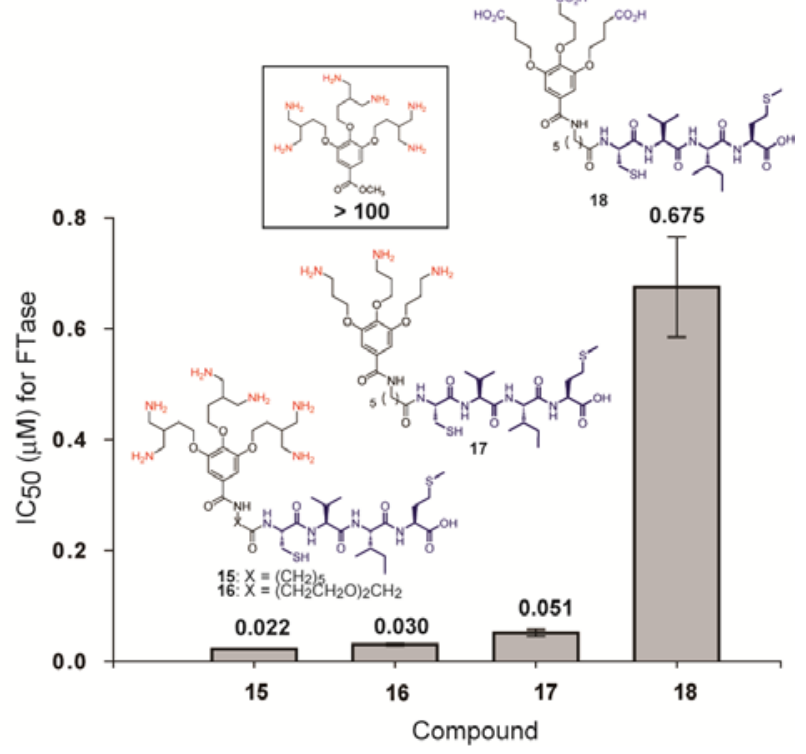

Fig. 12. (a) Dose-response curves for the inhibition of FTase and GGTase-I activity by the peptide CVIM and compound 15. (b) IC 50 values $(\mu \mathrm{M})$ for inhibition of FTase activity. Fluorescent in vitro assays were carried out using DansGCVIS $(1 \mu \mathrm{M})$ and FPP $(5 \mu \mathrm{M})$ in $50 \mathrm{mM}$ Tris-HCl buffer $(\mathrm{pH}$ $7.5)$ at $30^{\circ} \mathrm{C}$. 


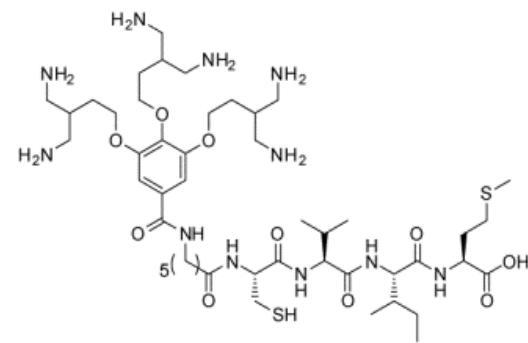

15

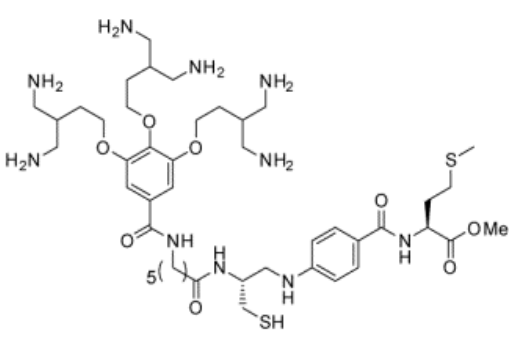

19

Fig. 13. Chemical structure of peptidomimetically modified bivalent compound 19. 